\title{
Study of the Spatio-emporal Distribution of Monitoring the Abundance and Diversity of Phytoplancton in Ivoirian Marine Waters using Remote Sensing
}

\author{
KOUADIO Maffoue ${ }^{1}$, BEUGRE Yves ${ }^{2}$, MOBIO Brice ${ }^{3}$, DJAGOUA Eric ${ }^{3}$ and KASSI Ahon ${ }^{3}$ \\ ${ }^{1,2,3}$ University Center for Research and Application in Remote Sensing (CURAT) \\ University of CoCody \\ BP: 801 Abidjan 22, \\ Ivory Coast
}

\begin{abstract}
In Côte d'Ivoire, knowledge of phytoplankton groups is a crucial issue for the development of economic activities and the prevention of health. It is in this context that was initiated: "study of the spatio-temporal distribution of the monitoring of the abundance and diversity of phytoplankton in the Ivorian marine waters by remote sensing ». This study showed a great diversity of phytoplankton in the Ivorian marine domain during the years 2009 and 2010. The data used are the concentration of chlorophyll a, the frequency of phytoplankton groups and the distribution of the dominant phytoplankton groups obtained using the MODIS, MERIS and SeaWiFS sensor. For the processing of these data, the PHYSAT method was used for the identification of phytoplankton groups. The SeaDAS v 7.4 software allowed to process and analyze the data. The spectral anomaly values $(R a)$ were obtained as well as the spatial distribution of the phytoplankton groups, thus allowing the realization of the maps of spectral anomalies $(\mathrm{Ra})$, and maps of spatial distributions of the phytoplankton groups.
\end{abstract}

KeyWords: Phytoplankton Groups, PHYSAT, Spectral Anomaly.

\section{INTRODUCTION}

The Ivorian marine domain has a large productive ecosystem and a great biological diversity, thus favoring the development of socio-economic activities and a large growth in the demography around the coast. The Ivorian marine ecosystem, also known as an upwelling ecosystem, is characterized by a variation of marine seasons. This upwelling phenomenon influences the evolution of phytoplankton which are the main food of several pelagic species. The nutrients transported to the surface by the upwelling contribute to the development of phytoplankton. Phytoplankton play an important role in the global carbon cycle through the fixation of inorganic carbon during photosynthesis, leading several researchers to focus on their biological aspects [2- 6, 9, 12, 13].

These studies have in common the use of several methods, including the remote sensing method based on the analysis of the spectral signatures of phytoplankton groups.

In the framework of this study, we are led to map the phytoplankton groups and to identify them from satellite data. To do this, the work will consist of :

- Producing spectral anomaly maps showing the evolution of the different phytoplankton groups in Ivorian marine waters;

- Identifying the most represented groups off the coast of Côte d'Ivoire.

Located in West Africa, more precisely at $5^{\circ} \mathrm{N}$ latitude, the Ivorian coastline represents only a small part of the large marine ecosystem of the Gulf of Guinea.

\section{MATERIALS AND METHODS}

\subsection{Presentation of the study area}

With a surface area of $2,325 \mathrm{~km}^{2}, 7 \%$ of the surface area of Côte d'Ivoire, the Ivorian coastline is $566 \mathrm{~km}$ long (Figure 1). The coastal environment is characterised by a vast lagoon system and the Ivorian coastline is divided into three main sectors [8]: 
- The western sector between Tabou, Sassandra and Fresco $(230 \mathrm{~km})$, oriented $70^{\circ} \mathrm{N}$;

- The central sector between Fresco and Abidjan (Port Bouet) $(190 \mathrm{~km})$, oriented $81^{\circ} \mathrm{N}$;

- The eastern sector between Abidjan (Port Bouet) and the border (100), oriented $101^{\circ} \mathrm{N}$.

The interlocking bathymetric curves show the presence of two submarine transform faults: the Saint Paul fault in the west and the Romanche fault in the east. The Ivorian coastline is fed by rivers that flow from north to south. There are two types of rivers. The first is made up of the four main rivers (the Cavally, the Sassandra, the Bandama and the Comoé, with respectively 30,000, $75,000,97,000$ and $78,000 \mathrm{~km}^{2}$ ), which have their source in the savannah zone, the second is made up of the coastal rivers, which have a hydrological regime that is more closely linked to the seasons in the coastal zone. The processed data are composed of images from the MODIS, MERIS and SeaWiFS sensors respectively for the mapping of phytoplankton groups. The data used were downloaded free of charge from the website (https://rsg.pml.ac.uk/thredds/ncss/grid/CCI_ALL-v4.2MONTHLY/dataset.html). As satellite data, we used chlorophyll a concentration data, and phytoplankton group frequency data from 2009 to 2010 .

The software we used was:

- $\quad$ SeaDAS for data extraction and processing of SeaWiFS satellite data ;

- Quantum GIS (QGIS) for map making and GIS applications ;

- Envi 5.3 for statistical data extraction.

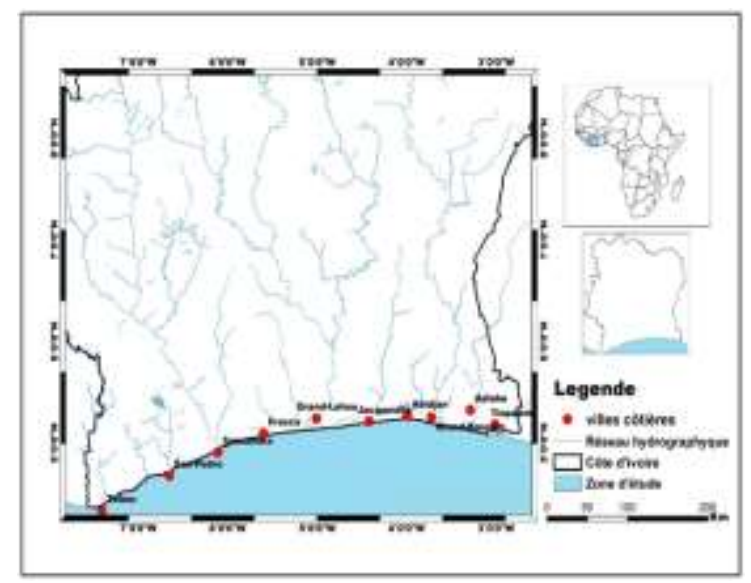

Figure 1. Map of the Ivorian marine coastline

\subsection{Study Methodology}

\subsubsection{Processing of the images}

The chlorophyll a concentration and phytoplankton group frequencies acquired have a level 3 (L3) processing, which means that our data have already undergone radiometric and atmospheric corrections. For the delimitation and division of the area we used the geographical coordinates of the Ivorian coast in the WGS 84 coordinate system.

\subsubsection{PHYSAT method}

PHYSAT is the method used in this study. It is a spectral approach that allows the detection of groups of phytoplankton [1-3]. This approach consists of using the second order variability of the spectral anomaly measurements (Ra or nLw) after removing the chlorophyll a concentration. Then, through in situ pigment measurements, this variability is used to identify different phytoplankton groups. The PHYSAT method also makes it possible to identify phytoplankton groups using in situ pigment data (chlorophyll a and other pigments) and coincident nLw data from the SeaWiFS sensor [1],[2]. The data used are level 3 (L3), daily images of chlorophyll a concentration, with aerosol optical thicknesses at $865 \mathrm{~nm}$ and normalized marine luminances (nLw) at 412, 443, 490, 510 and $555 \mathrm{~nm}$, some of which are taken simultaneously with the in situ pigment measurements. For Case 1 waters, the basic assumption of PHYSAT is that the shapes and amplitudes of the Ra spectra are related to the composition of phytoplankton groups. The second-order variability of $\mathrm{nLw}$ measurements is also called nLw anomalies, so-called spectral anomalies or Radiance Anomaly (Ra). The study of spectral anomalies which is the basis of the PHYSAT method is given by the equation (1):

$\operatorname{Ra}(\lambda)=\operatorname{nLw}(\lambda) / \operatorname{nLwref}(\lambda$, Chla $)(1)$ 
nLwref $(\lambda$, Chla), represents the average spectrum of $\mathrm{nLw}$ for a given chlorophyll a concentration, independently of the phytoplankton groups present at the time of the measurement. $\operatorname{Ra}(\lambda)$, corresponds to a quantity independent of the chlorophyll a concentration and represents the second order variation of $\mathrm{nLw}[1],[11]$.

\subsubsection{Analysis of spectral anomaly (Ra)}

This step consists in determining the spectral anomalies ( $\mathrm{Ra}$ ) in the different wavelengths 430, 490, 510 and 555. Indeed, each group of phytoplankton has a specific reflectance in each wavelength. In this step, the concentration of chlorophyll a is eliminated; the pixel values obtained after eliminating chlorophyll a correspond to the reflectances of the phytoplankton groups. The reflectances obtained correspond to the spectral anomalies $(\mathrm{Ra})$.

The spectral anomaly values are obtained using the algorithm $\operatorname{Ra}(\lambda)=n L w(\lambda) / n L w r e f(\lambda$, Chla), and are extracted using the SeaDAS software "Scheme nLw". Analysis of these values allows us to see the different wavelengths in which each phytoplankton group is identifiable. The chlorophyll a concentration data were used to highlight the spectral anomaly (Ra) maps. For the use of these chlorophyll a data, the chlorophyll a concentration must be :

- below an arbitrarily set maximum (at 3 or 5 mg.m-3 ) in order to reduce the probability of the presence of very strong blooms, not classified as case 1 , also potentially coastal and impacted by terrigenous matter ;

- and above 0.04 mg.m-3 in order to exclude ultra-oligotrophic waters where it becomes difficult to distinguish a dominant phytoplankton group.

Furthermore, in order to keep only good quality measurements, the optical thickness of aerosols at $865 \mathrm{~nm}$ must be less than or equal to 0.15 [1]. This threshold aims to minimise the impact of errors related to atmospheric corrections on the $\mathrm{nLw}$ [11].

\subsubsection{Extraction of spectral anomaly values (Ra)}

This step consists in extracting the values of the spectral anomalies ( $R a$ ) in the different wavelengths 430, 490, 510 and 555. Indeed, each $\mathrm{Ra}$ value is characteristic of a specific phytoplankton group in each wavelength. In this step, the Ra values are extracted from the pixel values obtained after applying the Scheme nLw algorithm in the SeaDAS software. The spectral anomaly values are obtained from the pixel extraction algorithm in SeaDAS or from a supervised maximum likelihood classification in ENVI. The analysis of these values allows to see the spatial distribution of phytoplankton groups in the different wavelengths in which each phytoplankton group is identifiable. The Ra values were used to highlight the mean curves of the distributions of Ra values from 2009 to 2010 in each wavelength.

\section{RESULTS AND DISCUSSION}

\subsection{Results}

\subsubsection{Spatial variability of spectral anomaly $(\mathrm{Ra})$ in 2009 to 2010}

MODIS, MERIS and SeaWiFS satellite images of chlorophyll a concentration were used to produce monthly maps of spectral anomalies (Ra), in different wavelengths. The spectral anomalies are also called second order variability of normalized marine luminances. The spectral anomaly maps obtained show the spatial distribution of phytoplankton groups in Ivorian marine waters. On the average map of spectral anomalies (Ra) in wavelengths below $430 \mathrm{~nm}$ of the Ivorian coastline from 2009 to 2010 , spectral anomalies are observed in the months January, February, March, April, May, November and December in small quantities with low and medium Ra values. The spectral anomalies (Ra) are precisely located in the southwest near the coastline. In June, July, August and September during the cold season, Ra values are visible all along the coastline from west to east in large quantities and can be observed off the coast of Côte d'Ivoire with medium and high Ra values. In October (transition period) these values are distributed from west to east along the coast with medium and high Ra values (Figure 2). 


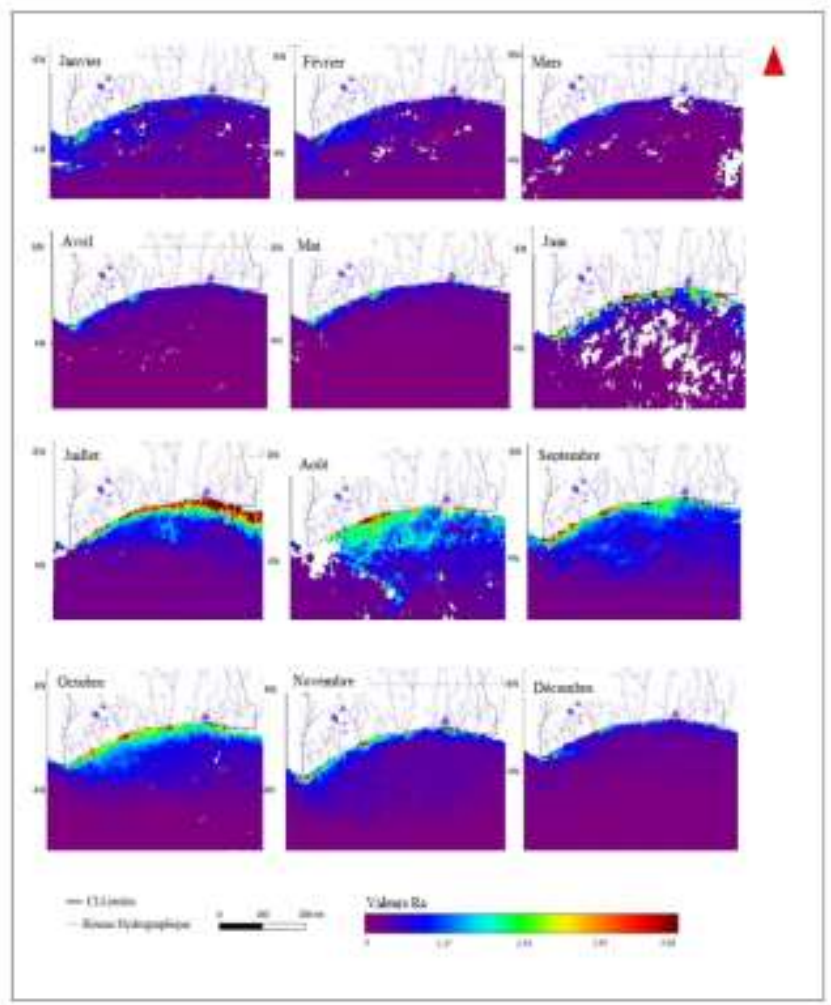

Figure 2. Average spectral anomalies (Ra) in wavelengths below $430 \mathrm{~nm}$ for the Ivorian coastline from 2009 to 2010

In the length range between $430 \mathrm{~nm}$ and $479 \mathrm{~nm}$, the spectral anomaly values (Ra) are visible all along the coast and are very abundant during the months of June, July, August and September with medium and high values. In October, the transition period, Ra values are observed along the coastline, generally medium towards the open sea and high towards the coast. During the months of November and December (short cold season) Ra values are observed more in November all along the coastline, in large quantities compared to December where these values are very low. In January, February, March, April and May, Ra values are observed towards the southwest of the coast with low values (Figure 3).

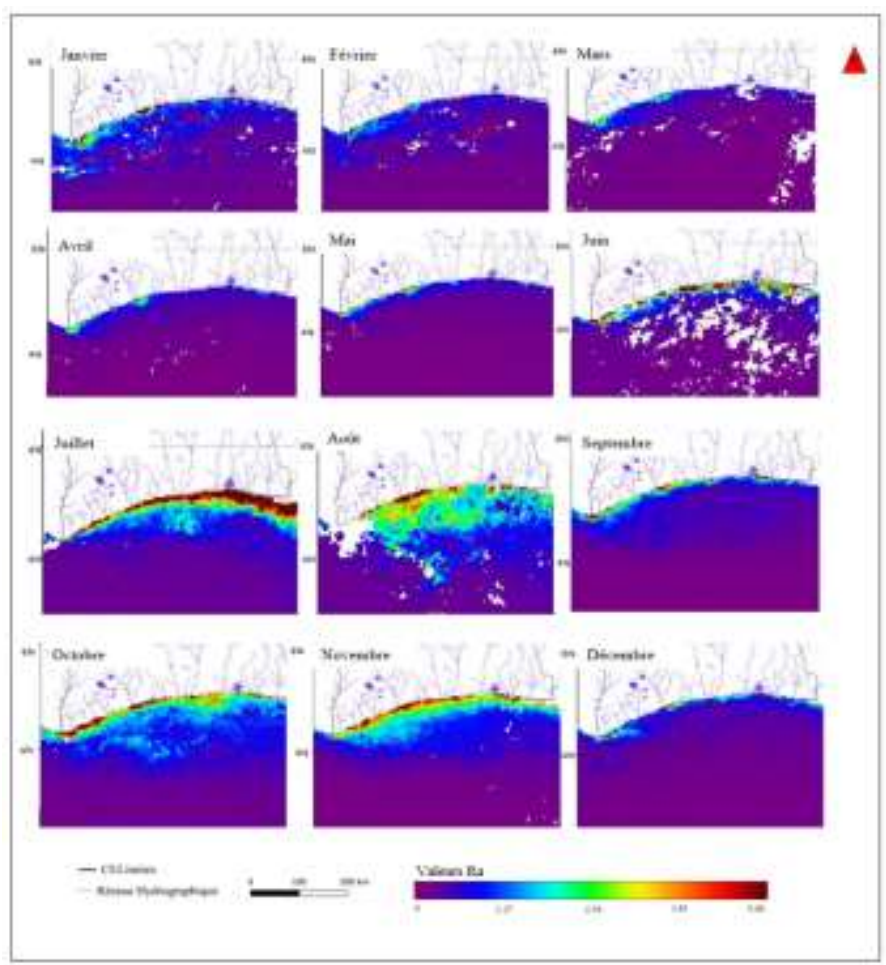

Figure 3. Average spectral anomalies (Ra) in wavelengths between $430 \mathrm{~nm}$ and $479 \mathrm{~nm}$ of the Ivorian coastline from 2009 to 2010 
In the wavelengths between $480 \mathrm{~nm}$ and $529 \mathrm{~nm}$ a spatial distribution is observed during the months. In the short cold season and the long hot season, Ra values are low and are located along the Ivorian coast. During the short cold season, the transition period (October) and the short warm season (November, December), Ra values are abundant in the open sea and along the coast, with values varying between low, medium and high (Figure 4).

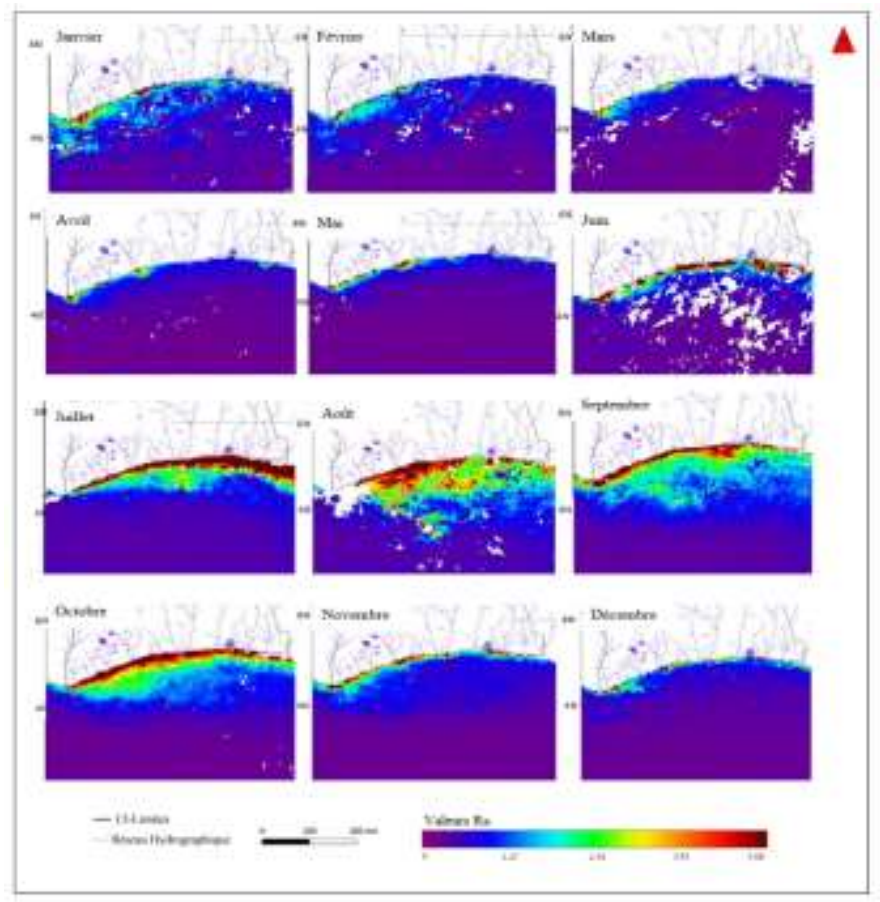

Figure 4. Average spectral anomalies (Ra) in wavelengths between $480 \mathrm{~nm}$ and $529 \mathrm{~nm}$ of the Ivorian coastline from 2009 to 2010

The average map of wavelengths between $530 \mathrm{~nm}$ and $599 \mathrm{~nm}$ shows Ra values distributed along the coast in all months. These values can be observed in large quantities in the months of June, July, August and September. These values are average off the coast and high along the coastline from west to east. These same characteristics are also observed in the other seasons (Figure 5).

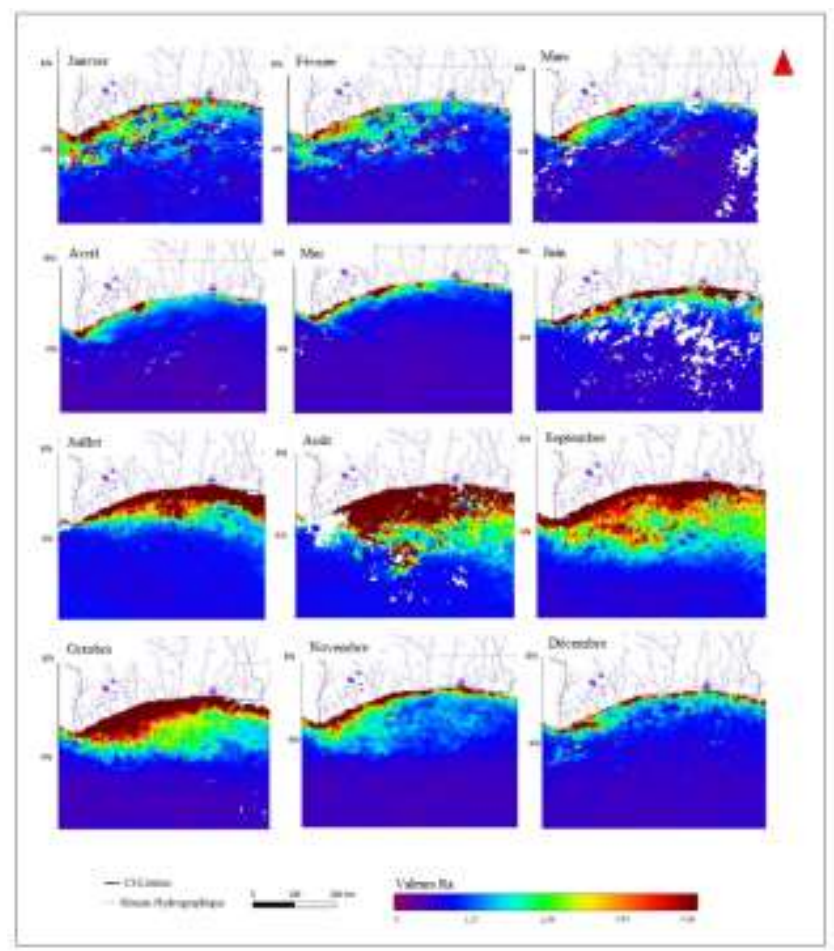

Figure 5. Average spectral anomalies (Ra) in wavelengths between $530 \mathrm{~nm}$ and $599 \mathrm{~nm}$ of the Ivorian coastline from 2009 to 2010 
The distribution of spectral anomaly values Ra in Ivorian marine waters in the different months could be due to the presence of oceanic marine currents. From April to June, a marine current called Guinea Current oriented from west to east could explain the almost centred position of Ra values in these months. In July the south-western location of the Ra values could be explained by the presence of the west-to-east oriented Guinea Current. In October the spatial distribution of Ra values could be explained by the presence of the two currents which are the Guinea Current and the Guinea Counter Current oriented towards the North.

\subsubsection{Spatial variability of Ra spectral anomaly values in 2009 to 2010}

The average spatial distribution of Ra values on the Ivorian marine coastline shows the spatial distribution of Ra values off the Ivorian coast from 2009 to 2010 (Figure 6). Three Ra values are observable in Figure 6, these are high Ra values, low Ra values and medium Ra values. These values are observable in almost all marine seasons. In the wavelengths below $430 \mathrm{~nm}$, the high Ra values whose peak reaches $30 \%$ during the period of the great cold season in July, are relatively less dominant. While medium Ra values with a peak of $80 \%$ during the long warm season in March and low Ra values with a peak of $80 \%$ during the short warm season (November) are largely dominant at wavelengths below $430 \mathrm{~nm}$ in almost all seasons.

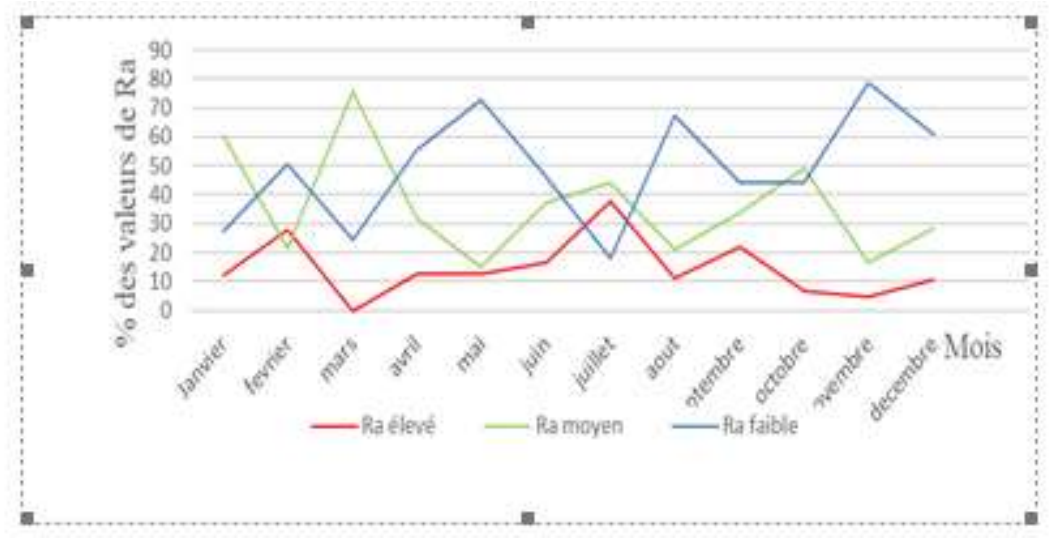

Figure 6. Spatial distribution of Ra values in the wavelengths below $430 \mathrm{~nm}$ of the Ivorian coastline from 2009 to 2010

The average spatial distribution of Ra values along the Ivorian coastline shows the spatial distribution of Ra values off the Ivorian coast from 2009 to 2010 (Figure 7). Three Ra values are also observable in Figure 7, these are high Ra, low Ra and medium Ra. These values are observable in almost all marine seasons. In the wavelengths between $430 \mathrm{~nm}$ and $479 \mathrm{~nm}$, high Ra values with a peak of $40 \%$ during the cold season in July and medium Ra values with a peak of $40 \%$ in the transition period (October) are relatively less dominant. While low Ra values with peaks of $95 \%$ and $80 \%$ during the short cold season (February) and the short warm season (November) largely dominate the Ivorian coastline in the wavelength range between $430 \mathrm{~nm}$ and $479 \mathrm{~nm}$ in almost all seasons.

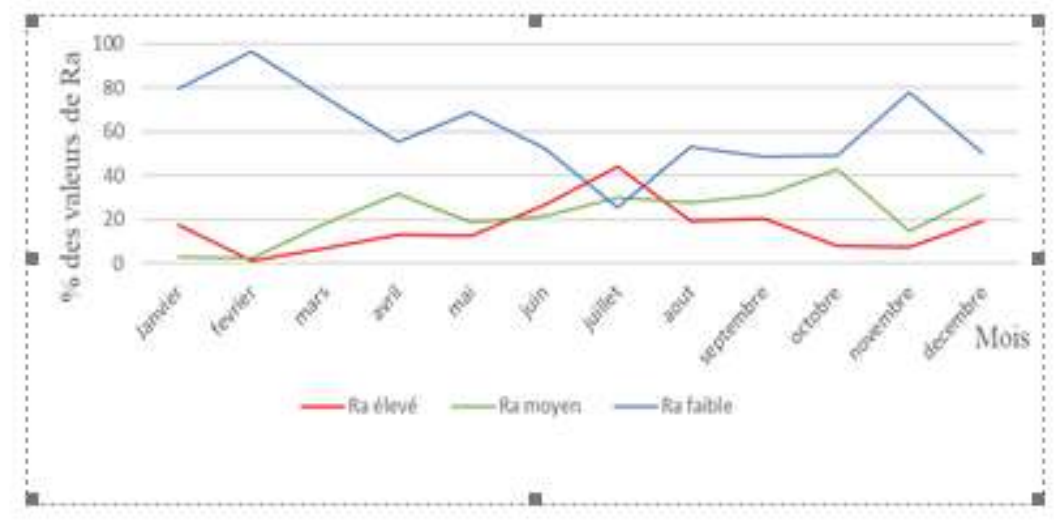

Figure 7. Spatial distribution of Ra values at wavelengths between $430 \mathrm{~nm}$ and $479 \mathrm{~nm}$ of the Ivorian coastline from 2009 to 2010

The average spatial distribution of Ra values over the Ivorian marine coastline shows the spatial distribution of Ra values off the Ivorian coast from 2009 to 2010 (Figure 8). Three Ra values are also observable in Figure 8, these are high Ra, low Ra and medium Ra. These values are observable in almost all marine seasons. In the wavelengths between $480 \mathrm{~nm}$ and $529 \mathrm{~nm}$, high Ra values with peaks of up to $40 \%$ during the major warm (April) and cold (July) seasons are moderately more dominant. Medium 
Ra values are less dominant with peaks of $28 \%$ and $32 \%$ in the short cold season (February) and the long cold season (August). While low Ra values with peaks of $75 \%$ and $62 \%$ during the short cold season (January) and the short warm season (November) and the long warm season (May) are also moderately dominant over the Ivorian coastline in the wavelengths between $480 \mathrm{~nm}$ and $529 \mathrm{~nm}$ in almost all seasons.

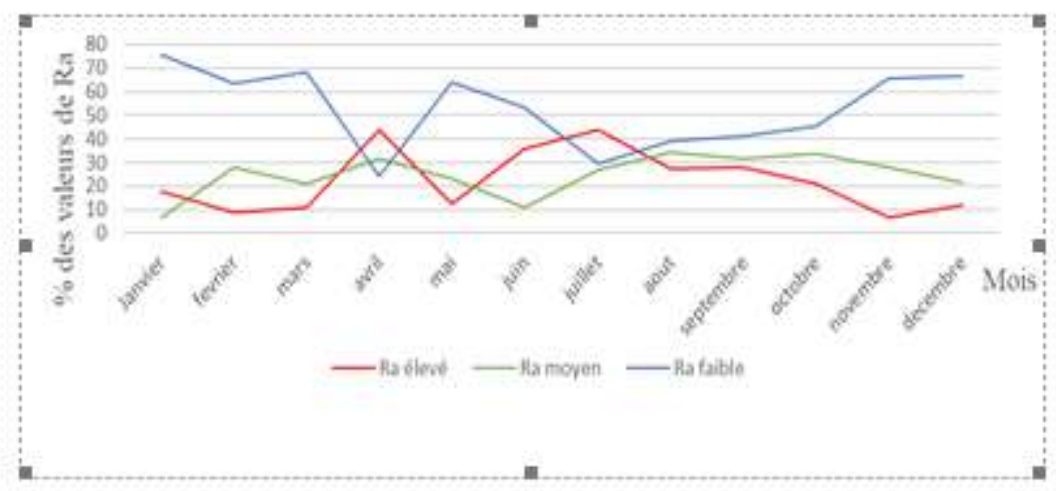

Figure 8. Spatial distribution of Ra values at wavelengths between $480 \mathrm{~nm}$ and $529 \mathrm{~nm}$ for the Ivorian coastline from 2009 to 2010

The average spatial distribution of Ra values over the Ivorian marine coastline shows the spatial distribution of Ra values off the Ivorian coast from 2009 to 2010 (Figure 9). Three Ra values are also observable in Figure 9, these are high Ra, low Ra and medium Ra. These values are observable in almost all marine seasons. In the wavelengths between $530 \mathrm{~nm}$ and $599 \mathrm{~nm}$, high Ra values with constant peaks of up to $43 \%$ during the main cold season (July, August, September) are moderately more dominant. Medium Ra values are also moderately dominant with a peak of 78\% during the cold season (March). While low Ra values with peaks of $65 \%$ and $62 \%$ during the short cold season (February) and the long hot season (May) and the short hot season (November) are also moderately dominant over the Ivorian coastline in the wavelengths between $530 \mathrm{~nm}$ and $599 \mathrm{~nm}$ in almost all seasons.

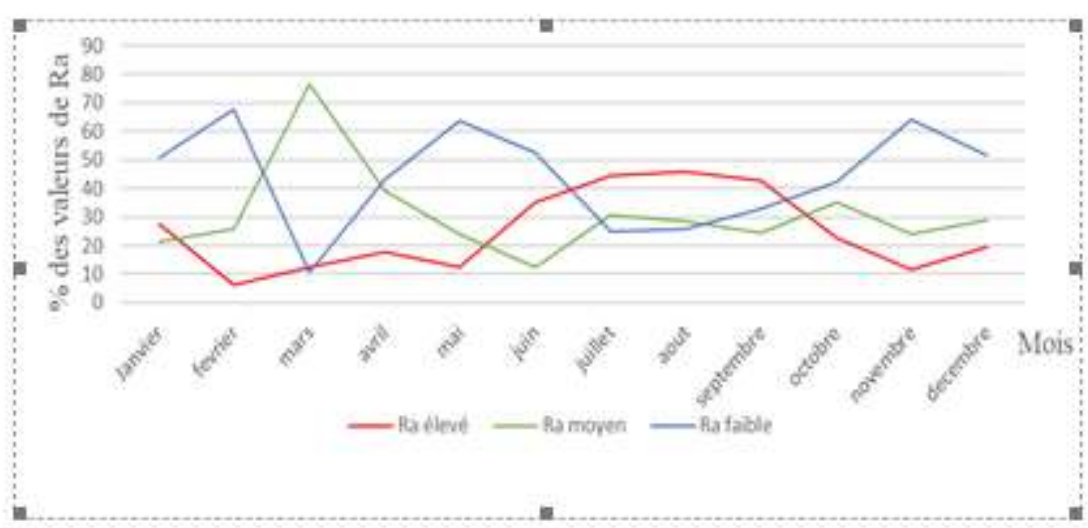

Figure. 9. Spatial distribution of Ra values at wavelengths between $530 \mathrm{~nm}$ and $599 \mathrm{~nm}$ of the Ivorian coastline from 2009 to 2010

\subsubsection{Relationship between spectral anomalies (Ra) and phytoplankton group frequency}

A relationship exists between the values of spectral anomalies $(\mathrm{Ra})$, and the appearance of the different phytoplankton groups in the Ivorian marine domain (Table 1). Coccolithophorids, diatoms and phaeocystis-like, are detectable in the long wavelengths $(480 \mathrm{~nm}, 530 \mathrm{~nm}$ and $599 \mathrm{~nm}$ ) with relatively strong spectral anomaly values (Ra), which is reflected in our memory by the variation of pixel values from the weakest ( 0 to 1.27) to the strongest pixel values (2.55 to 5.08). Prochlorococcus and synechococcus are detectable at long wavelengths $(530 \mathrm{~nm}$ and $599 \mathrm{~nm}$ ) with high spectral anomaly values (Ra) but also at short wavelengths (below $430 \mathrm{~nm}, 480 \mathrm{~nm}$ ) with medium spectral anomaly values (Ra), pixel values from 1.28 to 2.54 are observed. Nanoeukaryotes are characterised by low spectral anomaly values $(\mathrm{Ra})$ in the long wavelengths and relatively high spectral anomaly values $(\mathrm{Ra})$ in the short wavelengths (below $430 \mathrm{~nm}, 480 \mathrm{~nm}$ ). 
International Journal of Advances in Scientific Research and Engineering (ijasre), Vol 7 (11), November -2021

Table 1 : Reflectance of phytoplankton at different wavelengths

\begin{tabular}{|l|l|l|l|l|}
\hline $\begin{array}{c}\text { Wavelengths } \\
\text { Phytoplankton }\end{array}$ & Below $430 \mathrm{~nm}$ & $430 \mathrm{~nm}$ to $479 \mathrm{~nm}$ & $480 \mathrm{~nm}$ to $529 \mathrm{~nm}$ & $530 \mathrm{~nm}$ to $599 \mathrm{~nm}$ \\
\hline Coccolithophorids & Low Ra values & Medium Ra values & High Ra values & High Ra values \\
\hline Diatoms & Low Ra values & Low Ra values & High Ra values & High Ra values \\
\hline Nanoeukaryotes & High Ra values & High Ra values & Low Ra values & Low Ra values \\
\hline Phaeocystis-like & Low Ra values & Low Ra values & High Ra values & High Ra values \\
\hline Prochlorococcus & Medium Ra values & Medium Ra values & Medium Ra values & High Ra values \\
\hline Synechococcus & Medium Ra values & Medium Ra values & Medium Ra values & High Ra values \\
\hline
\end{tabular}

Legend: Low Ra values (0 to 1.27), Medium Ra values (1.28 to 2.54), High Ra values (2.55 to 5.08)

\subsection{Discussion}

The analysis of the chlorophyll data allowed the production of spectral anomaly maps in the wavelengths from $430 \mathrm{~nm}$ to $599 \mathrm{~nm}$. On these maps the Ra values vary between 0 and 5.81 in the different wavelengths. Low, medium and high Ra values were found and associated with the different wavelengths. Our results are in agreement with those of Alvain et al (2012) [3], who showed that phytoplankton groups are identifiable from $\mathrm{Ra}$ values that vary in the different wavelengths. Thus nanoeukaryotes are characterised by relatively low spectral anomaly $(\mathrm{Ra})$ values with an increase in values between short wavelengths (412 $\mathrm{nm}$ and $443 \mathrm{~nm}$ ) and prochlorococcus have higher spectral anomaly (Ra) values with a slight increase around 412 nm. Alvain (2005) [1], showed that diatoms are detectable by strong spectral anomaly values (Ra) with a decrease from 412 to $490 \mathrm{~nm}$. It appears from our results that the spectral anomaly values $(\mathrm{Ra})$ appear in the different months that correspond to marine seasons. This puts our results in relation with those of Lemasson and Rebert (1973) [7], who showed that the marine seasonal cycle was divided into several periods, including a transition period (October), two cold periods, a small one (January, February, March) and a large one (July, August, September), and two warm periods, a large one (April, May, June) and a small one (November, December).

The results provide information on the periods of appearance of different groups off our coasts. Some groups are observable in all seasons and others are observable in very specific periods. Nanoeukaryotes, coccolithophorids appear in all seasons too, Reyssac (1993) [11], shows that coccolithophorids are more abundant in warm periods than in cold periods. Zied Ben (2013) [14], shows that nanoeukaryotes are more abundant in cold periods than in hot periods. Both prochlorococcus and synechococcus are abundant in warmer periods and less abundant in cold periods and have an almost similar evolution during periods. Pedro $\mathrm{F}$ et al (2013) [10], showed that the similarity between these two groups is due to the fact that they belong to the cyanobacteria family. Zied Ben (2013) [14], also showed that prochlorococcus and synechococcus have characteristics similar to cyanobacteria by their spectral signature which confirms the results. Diatoms are abundant in the cold seasons but often appear in the small hot season. Reyssac (1993) also showed that diatoms are abundant in cold seasons and that some species such as Biddulphia sinensis and Hemiaulus membranaceus appear in certain warm periods, which in our work justifies the presence of diatoms in the month of December. Alvain (2008) [2], showed that phaeocystis like appear in seasons opposite to that of diatoms, which confirms the results, and showed the presence of phaeocystis-like in hot periods. The results made it possible to understand and assess the proliferation of groups phytoplankton in the Ivorian marine domain.

\section{GENERAL CONCLUSION}

The present study took place in the Ivorian marine domain, and the contribution of MODIS, MERIS and SeaWiFS satellite images to this study was of capital importance. The analysis of the satellite images allowed us to highlight the different periods during which phytoplankton are identifiable and characterisable.

The results of our work were obtained by applying the PHYSAT method. This method has two parts, a remote sensing part and a biological part which allows the identification of phytoplankton groups with pigment biomarkers. The analysis of the spectral anomaly values allowed the phytoplankton groups to be related to the different wavelengths. 
A more detailed and regular study of the Ivorian marine domain by satellite imagery seems necessary to identify other toxic phytoplankton. Thus, it will be necessary to:

- Study over a long series of years ;

- Carry out a campaign at sea to obtain in situ data, in order to better apply the PHYSAT method;

- Apply this methodology to more recent, high-resolution satellite images.

The study of these data will allow the identification of other groups of toxic phytoplankton and the assessment of the pollution status of Ivorian marine waters. This study will also allow a better understanding of the proliferation of phytoplankton and guide fisheries on the Ivorian continental shelf.

\section{REFERENCES}

[1] ALVAIN S., MOULIN C., DANDONNEAU Y., et BREON F. M. (2005). Remote sensing of phytoplankton groups in case 1 waters from global SeaWiFS imagery. Deep Sea Research I, 52 : 1989-2004.

[2] ALVAIN S., MOULIN C., DANDONNEAU Y., et LOISEL H. (2008). Seasonal distribution and succession of dominant phytoplankton groups in the global ocean: A satellite view. Global Biogeochemical Cycles, 22, GB3001, doi: $10.1029 / 2007$ GB003154.

[3] ALVAIN S., LOISEL H., et DESSALLY D. (2012). Theoretical analysis of ocean color radiances anomalies and implications for phytoplankton groups detection in case 1 waters. Optics Express, 20, 1070-1083

[4] BOPP L., MONFRAY P., AUMONT O., DUFRESNE L., TREUT H., MADEC G., TERRAY L., and ORR J. (2001). Potential impact of climate change on marine export production, Global Biogeochem. Cycles, 15(1).

[5] COX P., BETTS A., JONES C., SPALL S., and TOTTERDELL J. (2000). Acceleration of global warming due to carboncycle feedbacks in a coupled climate model, Nature, $408 \mathrm{P}$.

[6] DUFRESNES J., FRIEDLINGSTEIN P., BERTHELOT M, BOPP L., CIAIS P., FAIRDHEAD L., LE TREUT H., and MONFRAY P. (2002). On the magnitude of positive feedback between future climate change and the carbon cycle, Geophys. Res. Lett., 29(10), 1405, doi:10.1029/2001GL013777

[7] LEMASSON L., ET REBERT J-P. (1973). Courants marins dans le golfe ivoirien. Cah. ORSTOM, Sér. Océanogr., vol. XI, $\mathrm{n}^{\circ} 1, \mathrm{pp} .67-95$.

[8] LE LOEUFF P., ET MARCHAL E. (1993). Géographie littorale. In : Environnement et ressources aquatiques en Côte D’Ivoire. I-Le milieu marin. Paris, ORSTOM, p.15-22.

[9] THYSSEN M. (2008). Analyse à haute fréquence spatiale et temporelle du phytoplancton à l'aide de la cytométrie en flux automatisée et immergeable. Thèse de doctorat. pp.217

[10] PEDRO F., JOSE L., RODOLFO A., JOSE R, LINA L., NIANZHI J., DAVID M., WILLIAM K., MICHAEL W., DANIELE V., CAROLINA S., JASPER A., AND ADAM C. (2013). Present and future global distributions of the marine Cyanobacteria Prochlorococcus and Synechococcus. PNAS, vol.110, n²4.

[11] SEVRIN-REYSSAC J. (1993). Phytoplancton et production primaire dans les eaux marines ivoiriennes. In : Environnement et Ressources Aquatiques de la Côte d'Ivoire. I-Le milieu marin. Paris, ORSTOM, p.151-166.

[12] SMAYDA T.J. (1998) Patterns of variability characterizing marine phytoplankton, with examples from Narragansett Bay. ICES Journal of Marine Science Vol.55, Issue4, pp.562-573

[13] STOCKNER J.G., ANTI N.J. (1986). Algal picoplankton from marine and freshwater ecosystems: A multidisciplinary perspective. Can. J. Fish. Aquat. Sci. 43: 2472-2503

[14] ZIED B.M. (2013). Télédétection des groupes phytoplanctoniques via l'utilisation conjointe de mesures satellites, in situ et d'une méthode de classification automatique. Océanographie. Université du Littoral Côte d'Opale, p.1-33. 